ARTICLE

\title{
Evaluation of safety and performance of the self balancing walking system Atalante in patients with complete motor spinal cord injury
}

\author{
Jacques Kerdraon $^{1 凶}$, Jean Gabriel Previnaire ${ }^{2}$, Maegan Tucker ${ }^{3}$, Pauline Coignard ${ }^{1}$, Willy Allegre ${ }^{1}$, Emmanuel Knappen ${ }^{2}$ and \\ Aaron Ames $^{3}$
}

(c) The Author(s), under exclusive licence to International Spinal Cord Society 2021

STUDY DESIGN: Prospective, open label, observational.

OBJECTIVES: To present results of the first clinical study on a newly developed robotic exoskeleton (Atalante ${ }^{\circledR}$, Wandercraft, Paris, France) that enables individuals with spinal cord injury (SCl) to perform ambulatory functions without technical aids.

SETTING: Two sites specialized in SCI rehabilitation, France.

METHODS: Inclusion criteria were presence of chronic complete SCI (AIS A) ranging from T5 to T12. The study protocol included 12 one-hour training sessions during 3 weeks. Patients walked on floor with robotic assistance and wore a harness connected to a mobile suspension system (without weight-bearing) to prevent from falling.Main outcome was the ability to walk 10 meters unassisted, secondary outcomes were assessment of other ambulatory functions, bladder and bowel functions, pain and spasticity. RESULTS: Twelve patients were enrolled, and 11 completed the protocol, mean age 33,9 years. Six patients had T6 levels of lesion or above. Seven patients passed the $10 \mathrm{mWT}$ at the 12th session unassisted (mean walking speed $0.13 \mathrm{~m} / \mathrm{s}$ ) while four required some human help. All patients succeeded at the other ambulatory tests (stand-up, sit-down, balance, turn).There were no significant change for bladder (Qualiveen) or bowel (NBD) functions, neuropathic pain (NPSI, NPRS), yet five patients reported a subjective improvement of their bowel function. Impact on spasticity was variable depending on the muscle examined (Ashworth). Ischial skin erosion was seen in one patient that needed local dressing.

CONCLUSION: The Atalante system is safe and enables to perform ambulatory functions in patients with complete SCl.

Spinal Cord Series and Cases (2021)7:71; https://doi.org/10.1038/s41394-021-00432-3

\section{INTRODUCTION}

Despite a reduction in road accidents, the incidence of traumatic spinal cord injury $(\mathrm{SCl})$ remains high in France compared to the other trauma-induced disabilities [1]. The prevalence of this condition has increased in the US from 207,000 cases in 1994 to nearly 270,000 cases in 2012, as a result of increased life expectancy and better care in a population whose age of onset is below 40 years. Of all the functional impairments following $\mathrm{SCl}$, loss of ambulatory capacity ranks as one of the highest concerns in affected people [2].

Robotic exoskeletons that have opened new perspectives in enabling walking and standing up in daily living conditions for patients with $\mathrm{SCl}$, lifting two major technological barriers compared to conventional walking orthosis. First, they allow the relief of permanent visual control of lower limbs previously required to limit the hooking of the feet. Second, their reduced energy cost makes it potentially usable for patients with higher neurologic levels of injury. While powered robotic walking exoskeletons are proposed to restore functionality, their interest as an adjunct for neurorehabilitation still has little evidence $[3,4]$. Apart from the expected health benefit of daily-life bipedal locomotion, other considerations of feasibility, safety and speed are still to be investigated [5].

Two distinct technological approaches in walking robotics that are currently available include crutched and crutch-less exoskeletons. Crutched exoskeletons (such as ReWalk (ReWalk Robotics, Yokneam, Israel), Ekso (Ekso Bionics, Richmond CA, USA), Cyberdyne (Cyberdyne Inc, Tsukuba, Japan) or Indego (Parker Hannifin, $\mathrm{OH}, \mathrm{USA})$ ) require the user to supplement their balance with crutches [6]. While these devices usually offer a good walking speed, they present two major limitations: their architecture is restricted to four degrees of freedom (with only the knees and hips motorized) and their limited robotic capacity does not allow self-stabilization. In contrast, self-supporting robotic exoskeletons require no supplemental upper body support to balance. Until this study, the only device available was the REX Bionics (PLC, London, UK) which is a 12 motor driven degrees of freedom exoskeleton. However, constant static stability is achieved to the detriment of speed, much lower than physiological walking speed, as the software only allows for a quasi-static walk [7]. Moreover, the REX device is controlled by a joystick, which may limit the upper body kinetics required during physiological walking.

${ }^{1}$ Centre Mutualiste de Kerpape, Ploemeur Cedex, France. ${ }^{2}$ Centre Jacques Calvé - Fondation Hopale, Berck-sur-Mer Cedex, France. ${ }^{3}$ California Institute of Technology, Pasadena, CA, USA. ${ }^{凶}$ email: jkerdraon@kerpape.mutualite56.fr 


\begin{tabular}{|l|l|l|l|l|l|l|}
\cline { 2 - 6 } \multicolumn{1}{c|}{} & $\begin{array}{l}\text { Hip abduction/ } \\
\text { adduction }\end{array}$ & $\begin{array}{l}\text { Hip } \\
\text { lateral/medial } \\
\text { rotation }\end{array}$ & $\begin{array}{l}\text { Hip flexion/ } \\
\text { extension }\end{array}$ & $\begin{array}{l}\text { Knee extension/ } \\
\text { flexion }\end{array}$ & $\begin{array}{l}\text { Ankle dorsal } \\
\text { /plantar flexion }\end{array}$ & $\begin{array}{l}\text { Ankle } \\
\text { pronation/ } \\
\text { supination }\end{array}$ \\
\hline $\begin{array}{l}\text { Ranges } \\
\text { of motion }\end{array}$ & {$\left[17^{\circ} ; 10^{\circ}\right]$} & {$\left[20^{\circ} ; 10^{\circ}\right]$} & {$\left[115^{\circ} ; 15^{\circ}\right]$} & {$\left[0^{\circ} ; 110^{\circ}\right]$} & {$\left[16^{\circ} ; 9^{\circ}\right]$} & {$\left[18^{\circ} ; 18^{\circ}\right]$} \\
\hline
\end{tabular}
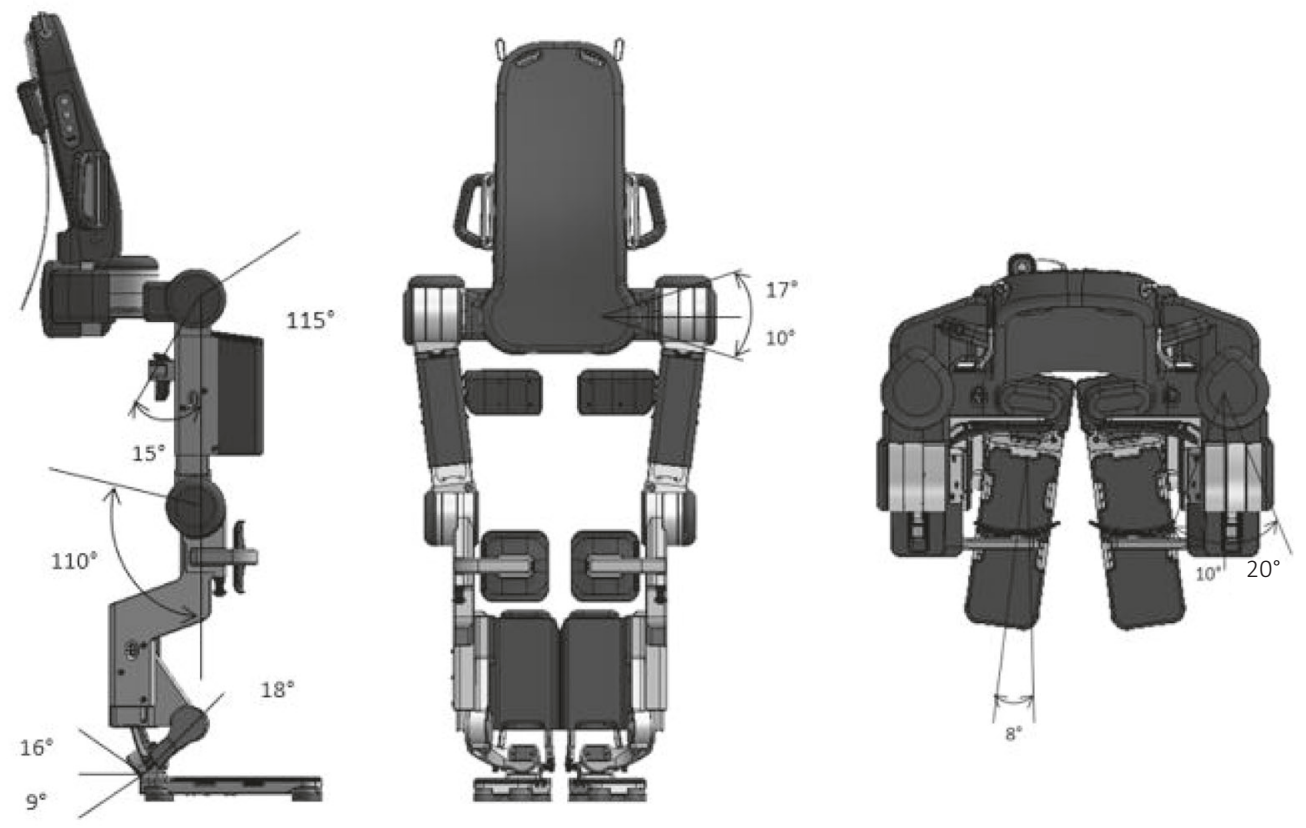

Fig. 1 Atalante exoskeleton and range of motions.

The Wandercraft device (Atalante) in its current version also features twelve degrees of actuation (six per leg) driven by 12 motors that are controlled by software that leverage the dynamics of the system. Its principle is radically different than the REX device since it is capable of dynamic motions that are periodically stable as opposed to statically stable.The mathematical framework capable of accomplishing dynamically stable walking on bipedal robots is the Hybrid Zero Dynamics (HZD) method and has been elsewhere described [8-10]. One of the technological challenges of the selfbalancing exoskeleton Atalante is therefore to utilize dynamic to eliminate the need for crutches while ensuring safety ambulatory functions in a comparable range of velocities. This article presents the first clinical outcomes of this framework as demonstrated for 12 subjects with complete motor $\mathrm{SCl}$ on the exoskeleton Atalante.

\section{METHODS}

This study was a prospective, open label, multicentric, non-randomized non comparative and observational study. Two sites specialized in $\mathrm{SCl}$ rehabilitation were involved in this trial.

\section{Description of the Atalante device}

The Atalante exoskeleton is composed of an external, powered, motorized orthosis that is placed over a person's paralyzed limbs to provide selfambulation functions without the use of crutches or other technical aids. The main feature of the exoskeleton is that it is fully-actuated with 12 actuated degrees of freedom: three at each hip, one at each knee, and two at each ankle (Fig. 1). The exoskeleton is attached to patient's legs in three areas (thigh, knee, foot) and on the torso with a belt and vest.

The study protocol included 12 one-hour training sessions during 3 weeks under the supervision of qualified Rehab teams. Patients walked on floor and wore a harness connected to a mobile suspension system (without weight bearing) to prevent from falling.

The participants were recruited from a $\mathrm{SCl}$ outpatient follow-up clinic. Table 1 summarizes inclusion/ exclusion criteria used for this study.
The primary endpoint was defined as the ability to walk 10 meters, without human or material assistance at the 12th session. The average walking speed was calculated from the total time (in seconds) to ambulate and the distance covered during the 10 meters walking test ( $10 \mathrm{~m} \mathrm{WT)}$. The stopwatch was started when the foot crossed the start point after a stabilization phase in the frontal plane for the first three steps.

The secondary endpoints were defined as the ability: to walk 10 meters, without human or material assistance at the 6th session; to sit down without human assistance, then maintain a balanced position for at least $5 \mathrm{~s}$; to stand still without support for $2 \mathrm{~min}$; to keep balance in exercise positions, with intrinsic perturbations such as arm and upper body movements; to observe the impact of the use of the Atalante system on cardiac function, pain (NPSI), bowel function (NBD, Bristol Stool Chart and Patient Global Impression of Improvement (PGI-I) at the last session),bladder function (Qualiveen Score), spasticity and to evaluate the ergonomics of Atalante exoskeleton [11-14]. The ability to turn $180^{\circ}$ in less than $3 \mathrm{~min}$ (U-turn) was also assessed, although it was added after the start of the study.

Each exercise test was completed by a rating of perceived exertions (RPE): developed by Gunnar Borg, the scale allows individuals to subjectively rate their level of exertion during exercise testing [15]. The perceived safety was evaluated after each exercise with a seven-point Likert scale on the following statement: "I felt safe during the test". The range of Likert scale captures the intensity of their feelings for a given item [16].

A record of any unexpected Serious Adverse Events (SAE) within trial episodes was kept. These are defined as death, a life-threatening adverse event or an event occurring as a result of the use of the device that requires medical intervention.

The study was registered on the ClinicalTrials.gov website (Clinical-Trials. gov identifier: 04110561) and had ethics committee approval from the French competent authority (ANSM on September 27th, 2018 and CPP Tours - Ouest 1).

\section{Statistical analysis}

The sample size calculation was based on the observed success rate (40\%) in a previous pilot study (i.e., $10 \mathrm{mWT}$ with continuous walking mode); a significant improvement of the performance was expected with the new generation [10]. A sample size of 12 patients had been deemed necessary 
Table 1. Inclusion and exclusion criteria.

\section{Inclusion Criteria}

- Complete traumatic Spinal Cord Injury (AIS A) since at least 4 months

- Male or female, between 18 and 65 years of age

- Spinal Injury Level between AIS T5 and AIS T12

- Able to verticalize on a daily basis

- Height: between approximately 1.60 and $1.90 \mathrm{~m}$.

- Atalante is able to accommodate the following limb lengths:

- Thigh: $380-460 \mathrm{~mm}$

- Distance between the ground and the joint space of the knee (to be measured while wearing the shoes they intend to wear with Atalante):

O 457-607 $\mathrm{mm}$ for patient with an ankle dorsiflexion $\geq 16^{\circ}$

O $457-577 \mathrm{~mm}$ for patient with an ankle dorsiflexion between $13^{\circ}$ et $16^{\circ}$

O $457-567 \mathrm{~mm}$ for patient with an ankle dorsiflexion between $10^{\circ}$ et $13^{\circ}$

- 457-557 $\mathrm{mm}$ for patient with an ankle dorsiflexion between $0^{\circ}$ and $10^{\circ}$

Hip width less or equal to $460 \mathrm{~mm}$ when seated

- Maximum weight:90 kg

- Patient having given his written consent

\section{Exclusion Criteria}

- Patients whose joint centers cannot be aligned Atalante's

- Ranges of motion below:

O Knee: $5^{\circ}$ extension, $110^{\circ}$ flexion

Ankle: $0^{\circ}$ dorsiflexion, $9^{\circ}$ plantar flexion, $18^{\circ}$ inversion and eversionHip: $115^{\circ}$ flexion, $15^{\circ}$ extension, $17^{\circ}$ abduction, $10^{\circ}$ adduction, $10^{\circ}$ medial rotation, $20^{\circ}$ lateral rotation

- Severe spasticity (greater than Ashworth 3) or uncontrolled clonus

- Severe concurrent medical diseases: infections, irculatory, heart or lung, pressure sores

- Psychiatric or cognitive comorbidities that may interfere with the trial

- Heterotopic ossification that restricts functional range of motion

- History of other neurologic disease

- Active implantable medical device

- Known syringomyelia

- Pregnancy or lactating

Table 2. Demographics of the population.

\begin{tabular}{|llllllll}
\hline Patient & Sex & Age & Height & Weight & ASIA level of injury & Time since injury (month) \\
\hline 1 & Female & 35 & 180 & 60 & T10 & 136 \\
\hline 2 & Male & 31 & 184 & 70 & T6 & 143 \\
\hline 3 & Male & 50 & 187 & 73 & T6 & 14 \\
\hline 4 & Male & 18 & 183 & 60 & T6 & 34 \\
\hline 5 & Male & 41 & 174 & 50 & T6 & 218 \\
\hline 6 & Male & 33 & 175 & 62 & T10 & 152 \\
\hline 7 & Male & 26 & 180 & 70 & T12 & 12 \\
\hline 8 & Male & 39 & 177 & 65 & T8 & 58 \\
\hline 9 & Female & 35 & 164 & 65 & T5 & 75 \\
\hline 10 & Male & 45 & 178 & 75 & T12 & 96 \\
\hline 11 & Male & 21 & 168 & 73 & T5 & 79 \\
\hline 12 & Male & 33 & 175 & 75 & T11 & 40 \\
\hline Mean & & 33.9 & 177 & 67 & & 88 \\
\hline Standard deviation & & 9.3 & 6.5 & 7.6 & & 63.2
\end{tabular}

to demonstrate the performance ( $78 \%$ for the new generation vs $40 \%$ for the previous generation), with an alpha risk of $5 \%$ and a statistical power of 80\% (Two-sided test).

Descriptive statistics (i.e., mean, standard deviation) were calculated for quantitative data (demographics and clinical characteristics and outcome measures). Frequencies were calculated for qualitative variables.

For the proportions, binomial proportion confidences were calculated using the Wilson formulae. Proportions were compared using the Newcombe formulae [17].

The Wilcoxon bilateral matched-pairs test was used to compare repeated measurement on a single sample (mean, standard deviation).
Ordered ordinal variables of the 6th and the 12th sessions were compared using a contingency table to make intra-patient comparison. The sign test counted positively patients with an improvement, negatively patients with an aggravation, and did not count patients with no change [18].

\section{RESULTS}

The characteristics of the sample population are shown in Table 2 and follows the International Standards for Neurological Classification of Spinal Cord Injury (ISNCSCI) [19]. Twelve patients were 


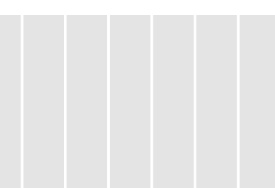

$\circ m \circ \wedge$

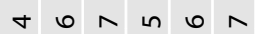

ị

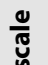

ํํํ

$m \circ \mathrm{m}+$
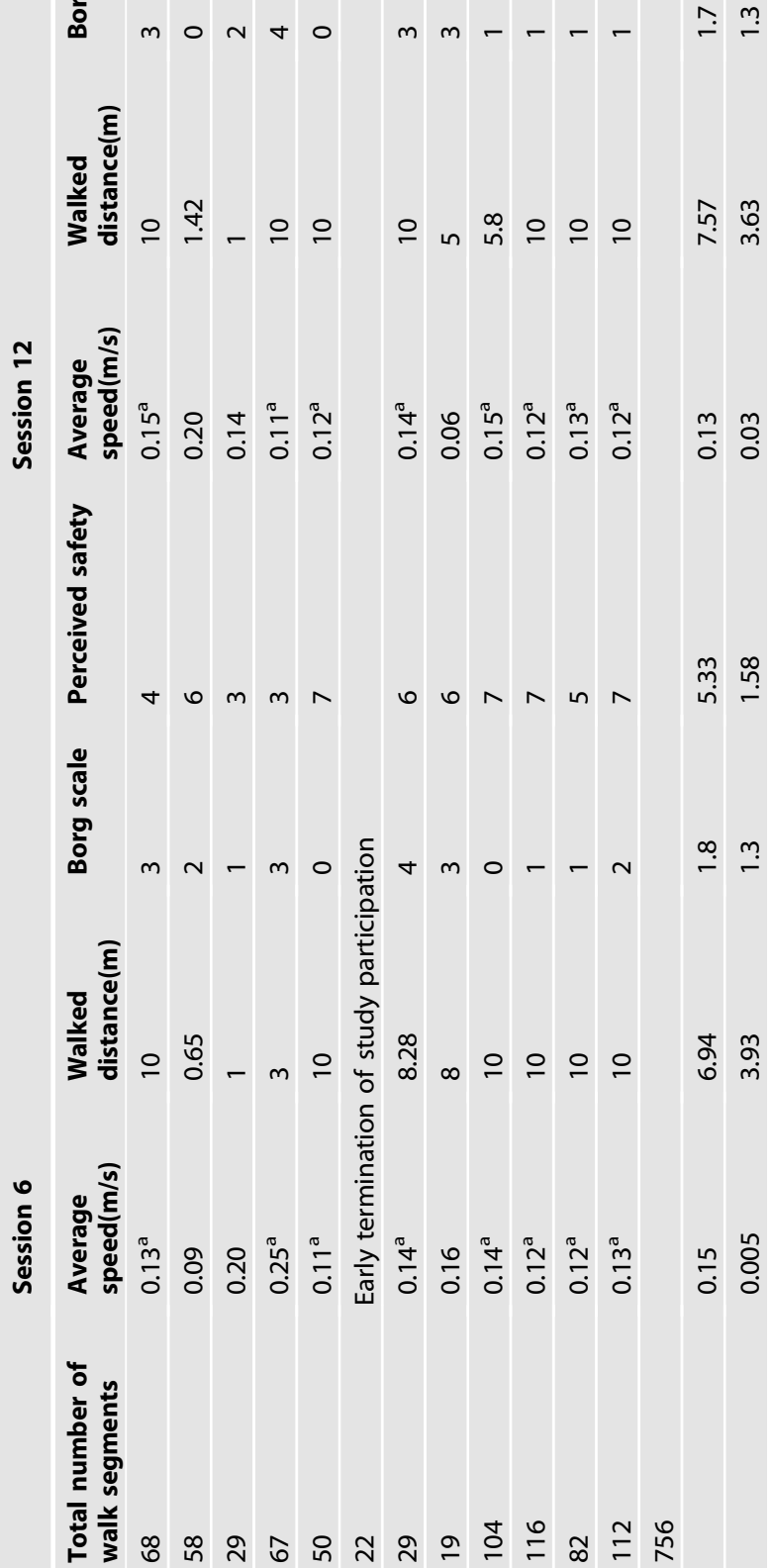

œ

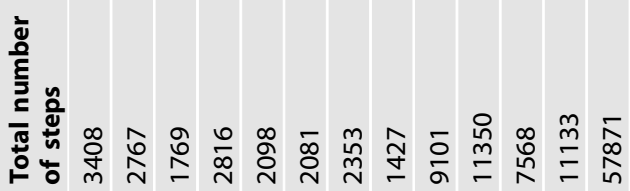

䓪 enrolled in the study, six in each site. One patient withdrew from the study for professional reasons after session 6 .

\section{Walking parameters}

Ten of the 12 patients started using the walk mode from the first session, whereas the other two started using this mode at the second and third session. Seven out of 11 patients passed the $10 \mathrm{mWT}$ unassisted at the 12th session, representing $63.6 \%$ of success. The remaining four patients walked between one and 5.8 meters unassisted and were still able to walk the remaining of the 10 meters with human assistance. The proportion of success increased from the 6th to the 12th session, as two patients that failed the $10 \mathrm{mWT}$ at the 6 th session passed it at the 12th, while the opposite was found for one patient. No relationship was observed with age, gender, height, weight or level of injury. The patient who withdrew from the study after the 7 th session had failed the $10 \mathrm{mWT}$ at the 6 th session. For the three patients who failed to pass the $10 \mathrm{~m}$ WT at both the 6 th and 12th sessions, no relationship was further observed with the different metrics of postural and trunk control.

The walking speed for the patients who participated in the $10 \mathrm{mWT}$ ranged from $0.06 \mathrm{~m} / \mathrm{s}$ to $0.25 \mathrm{~m} / \mathrm{s}$ (Table 3). For the patients who passed the $10 \mathrm{mWT}$ with no assistance at the 6 th or 12th session, the average speed was $0.13 \mathrm{~m} / \mathrm{s} \pm 0.01$, with no statistical difference between the sessions $(p=0.77)$

Mean perceived safety was 5.30, which reflects a feeling between "agree somewhat" to "agree" to the affirmation "I felt safe during this test". Two patients did not feel safe ("disagree somewhat") at the 6th session, out of whom one improved to feeling safe ("agree"), leaving only one patient not feeling safe at the 12th session. It's interesting to note that the two patients who didn't feel safe failed the 10mWT and that both had T6 level of injury).

Mean RPE on the Borg CR-10 was 1.3 (between very easy and somewhat easy) and ranged from 0 to 4 ("somewhat hard").

\section{Postural parameters}

All patients succeeded in standing up, sitting down and standing up for two min at the 6 th and 12th session. The four patients who failed to lean forward more than $25 \mathrm{~cm}$ at session 6 had T6 and T5 level of injury. At the 6th session, all the patients passed the U-turn test with some assistance, whereas during the 12th session two patients performed the U-turn without any help. Comparison for perceived safety and RPE at Session 6 and 12 for all skills were not statistically significant.

\section{Adverse events}

Five patients presented skin redness after some of the sessions. Particular care was taken with the placement of the patient straps, and skin redness resolved rapidly without sequelae for four of them. One patient later developed unilateral ischial skin abrasion that required additional local dressing, and the skin eventually healed. One patient had a redness before the first session, which later disappeared.

Furthermore, two patients had non febrile urinary tract infection during the study, but none were attributed to the study.

\section{Physiological effects}

The influence of the use of Atalante on pain, bowel and bladder function are shown in Table 4. No statistical differences were observed between the sessions 6 and 12, except a clear trend on the Bristol score assessing the bowel function $(p=0,06)$.

The average heart rate $(\mathrm{HR})$ at rest at the 1 st session was 86 bpm, which is within normal range (from 60 to $100 \mathrm{bpm}$ ) and was $104 \mathrm{bpm}$ at the 12th session. The average HR at rest and after the $10 \mathrm{mWT}$ was statistically different at both the 6 th $(p=0.04)$ and 12 th session $(p=0.01)$, whereas no significant 
Table 4. Results of the Qualiveen score, Neurogenic Bowel Dysfunction (NBD), Bristol Stool Chart, Neurogenic Pain Symptôm Inventory (NPSI) at rest and at the 12th session, Patient Global Impression of Improvement (PGI-I) on the bowel function at the 12th session.

\begin{tabular}{|c|c|c|c|c|c|c|c|c|c|}
\hline \multirow[t]{2}{*}{$N=11$} & \multicolumn{4}{|l|}{ Rest } & \multicolumn{5}{|l|}{ S12 } \\
\hline & Qualiveen & NBD & Bristol & NPSI (/100) & Qualiveen & NBD & Bristol & NPSI (/100) & PGI-I \\
\hline & 0.55 & 12 & 5 & 5 & 0.93 & 2 & 5 & 6 & 2 \\
\hline & 0.3 & 6 & 1 & 14 & 0.515 & 11 & 3 & 18 & 4 \\
\hline & 0.03 & 6 & 3 & 4 & 0 & 6 & 3 & 4 & 4 \\
\hline & 0.06 & 12 & 6 & 0 & 0.06 & 6 & 5 & 0 & 2 \\
\hline & 0.65 & 13 & 2 & 2 & 0.25 & 11 & 1 & 2 & 4 \\
\hline & 0.68 & 9 & 3 & 0 & 0.85 & 9 & 3 & 0 & 4 \\
\hline & 0.03 & 2 & 3 & 2 & 1.35 & 2 & 5 & 0 & 3 \\
\hline & 1.32 & 19 & 3 & 6 & 0.78 & 25 & 4 & 8 & 3 \\
\hline & 0.99 & 1 & 7 & 0 & 0.99 & 1 & 5 & 1 & 3 \\
\hline
\end{tabular}

The values reported are the total scores calculated for the Qualiveen, the NBD and the NPSI.

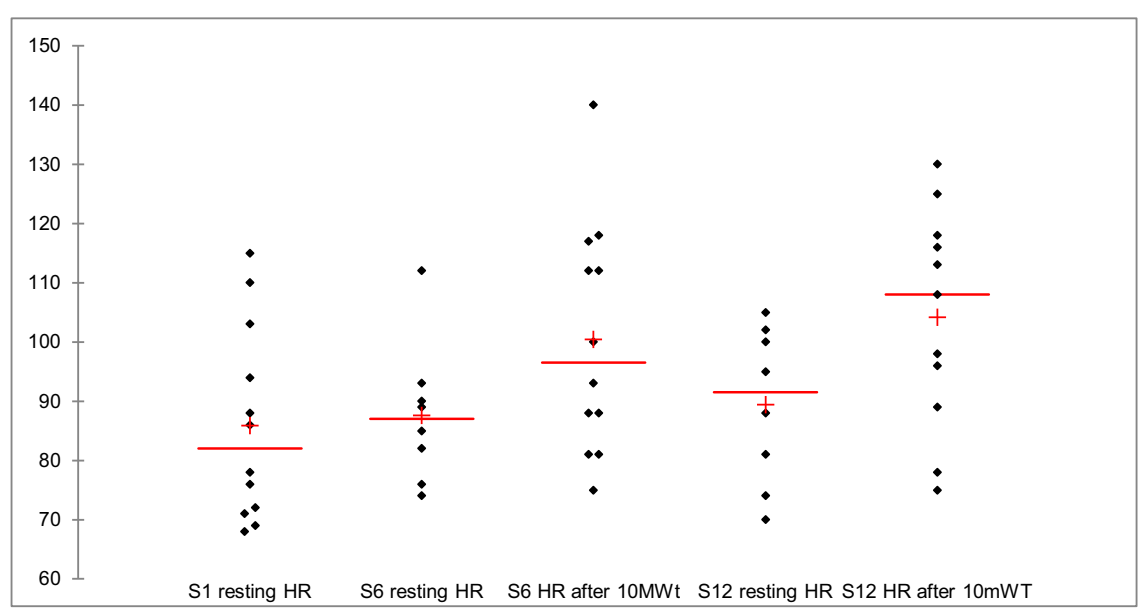

Fig. 2 Heart rate during sessions. Influence of walking on heart rate, respectively at rest at the 1 st session, before and after the $10 \mathrm{mWT}$ at the 6th and 12th session for the 11 patients who completed the study.

change in at rest HR has been shown between beginning and end of the study (Fig. 2). No significant relations were found between HR and RPE on the Borg Scale at Session 6 and 12.

\section{DISCUSSION}

To our knowledge, this is the first report of persons with motorcomplete paraplegia performing community-based skills in a dynamic self-stabilizing robotic exoskeleton.

Several significant results are to be highlighted in this initial feasibility study. First, most patients were able to walk from the first session and all 11 patients were able to walk some distance unassisted at the 12th session: seven passed the $10 \mathrm{mWT}$ (64\%) while the other four walked between one and 5.8 meters. The rate of success for walking without assistance increased from the 6 th to the 12th session, suggesting that learning and training with Atalante exoskeleton is effective. For the patients who failed to walk $10 \mathrm{~m}$ without aid at the last session, analysis of the adaptation of the user over more sessions will be required since Atalante deviates from the motor patterns usually required in patients with $\mathrm{SCl}$ for standing up or walking with crutches. The same adaptation process through training was also observed regarding the feeling of safety during the test, as one patient who did not feel safe at the 6th session, felt safe at the 12th.

Second, the mean unassisted walking speed in our study was $0.13 \mathrm{~m} / \mathrm{s}$ for all the 11 patients at the last session. The mean walking speed observed at the first session $(0.15 \mathrm{~m} / \mathrm{s})$ was three times higher than the speed of $0.05 \mathrm{~m} / \mathrm{s}$ selected for other selfsupporting devices [7]. The mean forward velocity for the patients who did not successfully complete the $10 \mathrm{~m}$ WT varied more significantly with a high disparity between subjects (Fig. 3). One explanation is that the measured distance did not correspond to the real walked distance because the exoskeleton was no longer following a rectilinear trajectory during the $10 \mathrm{~m} \mathrm{WT}$, and this concerned the less experienced patients who had a lower total number of steps realized during the entire study.

Walking with exoskeletons that utilize arm-crutches is reported to exhibit a mean gait speed between 0.26 and $0.46 \mathrm{~m} / \mathrm{s}$, with an individual participant speed ranging from 0.0031 to $0.71 \mathrm{~m} / \mathrm{s}$ [20]. This demonstrated walking speed is correlated with level of lesion and number of training sessions. In our study, patients appear to 


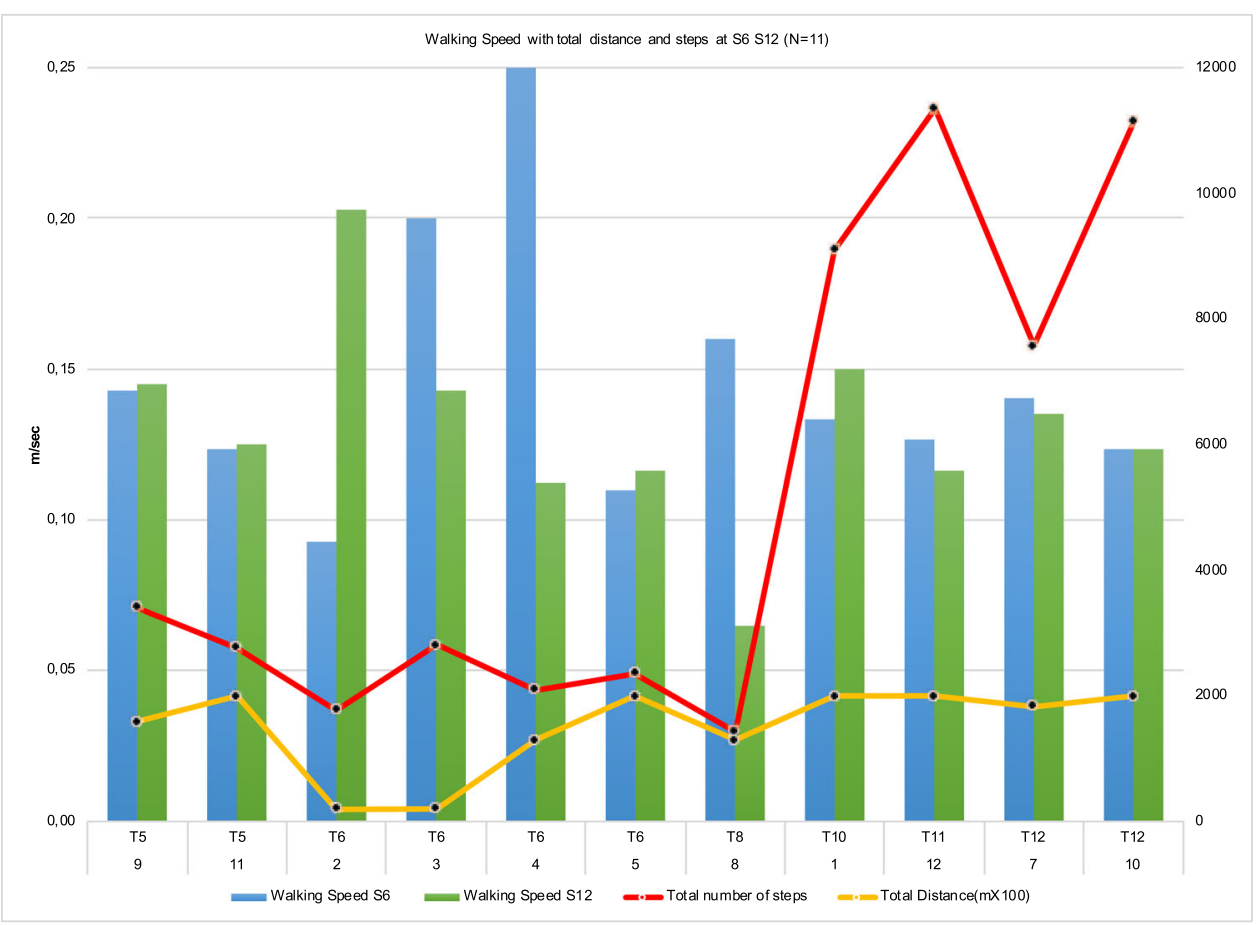

Fig. 3 Gait abilities. Graphical representation of gait performance on the $10 \mathrm{mWT}$ at the 6 th and 12 th sessions plotted with total number of steps during the entire study for the 11 patients according to their level of injury. It can be seen that some metrics varied significantly between patients (number of steps, estimated walked distance, average forward velocity).

walk autonomously for longer distances in the device and feel increasingly safe over time. This suggests that training might influence the patient's capacities with the device, even though most patients are able to walk the first time they use the system. Van Hedel and colleagues demonstrated that persons recovering from incomplete $\mathrm{SCl}$ (AIS C and D) who could walk (with aid) at a minimum velocity of $0.44 \pm 0.14 \mathrm{~m} / \mathrm{s}$ or better were able to walk outdoors [21]. The velocity observed in this study was $0.06-0.25 \mathrm{~m} / \mathrm{s}$. The Atalante system could therefore ensure ambulatory functions with comparable speed while leaving upper limbs free for additional tasks, with the advantage of preventing additional damage to the shoulders. No statistical difference was observed when comparing performance in ambulatory functions at the 6th and 12th sessions. This may suggest that patients are quickly able to properly use the system, leading to an optimal use as early as before the 6th session. Since no specific cause was found for the three patients who never achieved the $10 \mathrm{mWT}$ without assistance, we believe that some patients need more training sessions than others, and that the performance reached with the Atalante system also depends on the physical and psychological conditions of the subject.

Exoskeleton sessions during the 10mWT significantly increased patients $\mathrm{HR}$, as previously observed in motor complete $\mathrm{SCl}$ patients using powered exoskeletons assisted with crutches $[22,23]$. This might indicate that Atalante training also modifies the cardiovascular response and may be involved in effort retraining. We also didn't find any relation between RPE and HR variation after walking sessions. As HR is believed to be a good indicator of metabolic strain, the perception of exercise intensity may thus be influenced by psychological factors such as motivation or exercise experience.

Some studies have shown that the use of an exoskeleton can improve spasticity, bowel and bladder function [3]. We observed a slight improvement of the bowel function similar to other studies, without any significant benefits regarding the other assessed functions [24].

The preservation of upper limb functionality is a high priority for all of these patients in whom the estimated lifespan with a $\mathrm{SCl}$ is now almost 32 years, and is a prerequisite for generalizing the use of these devices in everyday use [25]. It is also well known that the release of upper extremity support improves the performance of functional tasks while using walking exoskeletons [26]. The ability of the patient to lean with arms extended in a standing position (arms abducted $90^{\circ}$ ) still remains a great challenge for patients with level of injury above T6. The measurements show differences related to levels of lesion in complete $\mathrm{SCl}$ and can be correlated with scores on clinical tests of function $[27,28]$. We used the Boubee scale which assesses the ability of the subject to balance in sitting position with perturbations induced by movements of the upper limbs [29]. Only one patient in our study could not lean forward more than $25 \mathrm{~cm}$ while upstanding in the Atalante at the 12th session. This result could be explained by the high level of injury of the patient concerned (T6) forcing him to use the shoulder straps to keep his back straight, which reduces his capacity to lean. Surprisingly, no relations were found between the Boubee score, safety, or RPE and postural abilities for those patients (Fig. 4), which means that physical, but also psychological factors, may account for these differences.

This first feasibility study did not analyze the kinematic parameters of the upper limbs and shoulder girdles of this crutch-less gait pattern. Cycling arm movements during gait are known to generate modulatory effects on lower limb muscle activation related to plasticity of spinal circuits [30]. This could be exploited to enhance targeted rehabilitation strategies and augment neuroplasticity after neurologic damage [31].

\section{Limitations}

Nevertheless, this study presents limitations related to the small sample size of patients and the absence of a control group. During this study, concomitant treatments were not recorded as well. These treatments may have an impact on the spasticity, HR, pain, bowel and bladder function. All physiological recorded measurements have evaluated the impact of the Atalante device and the potential impact of a non-recorded treatment. 


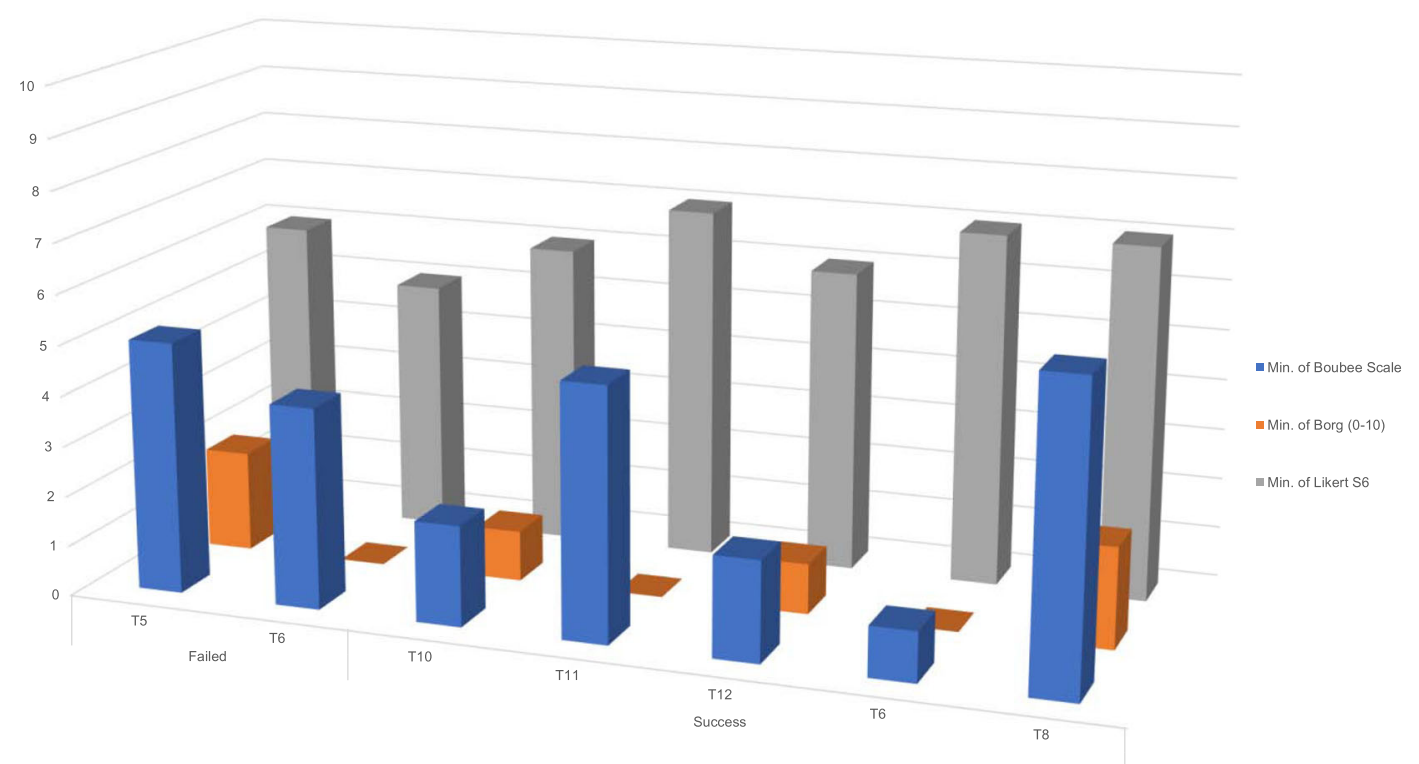

Fig. 4 Postural abilities. Representation of the Boubee score, the Borg scale and RPE for the 11 patients according to the ability to lean forward more than $25 \mathrm{~cm}$ at the 6 th and according to the level of injury.

The device still needs to be secured by a safety line or a therapist behind the patient. Software development based on the mathematical framework mentioned above are however in progress to move in more complex ambulatory environment such as slopes or stairs, and to move towards autonomous locomotion.

\section{CONCLUSION}

The Atalante self-balancing walking exoskeleton enables ambulatory functions in persons with motor complete $\mathrm{SCl}$, including walking, verticalizing, sitting down, turning and performing dynamic balance exercises. Adverse events were limited to skin lesions that showed prompt resolution without sequelae.

Further trials should challenge its use in other populations, such as those patients with an incomplete $\mathrm{SCl}$ or a cervical $\mathrm{SCl}$ and complete tetraplegia. The adaptation process for ambulation should be further assessed with longer duration of training. In addition, certain clinical parameters including spasticity, pain, fatigue, bowel and bladder function should be reevaluated with a larger sample of patients. Finally, the dynamic behaviors on the exoskeleton can be expanded to include natural, efficient and robust gaits that enable locomotion in natural environments.

\section{DATA AVAILABILITY}

The datasets analysed during the current study are available from the corresponding author on reasonable request.

\section{REFERENCES}

1. Lieutaud T, Ndiaye A, Laumon B, Chiron M. Spinal cord injuries sustained in road crashes are not on the decrease in france: a study based on epidemiological trends. J Neurotrauma. 2012;29:479-87.

2. Brown-Triolo DL, Roach MJ, Nelson K, Triolo RJ. Consumer perspectives on mobility: implications for neuroprosthesis design. J Rehabil Res Dev. 2002;39:659-69.
3. Miller LE, Zimmermann AK, Herbert WG. Clinical effectiveness and safety of powered exoskeleton-assisted walking in patients with spinal cord injury: systematic review with meta-analysis. Med Devices (Auckl). 2016;9:455-66.

4. Mehrholz J, Harvey LA, Thomas S, Elsner B. Is body-weight-supported treadmill training or robotic-assisted gait training superior to overground gait training and other forms of physiotherapy in people with spinal cord injury? A systematic review. Spinal Cord. 2017;55:722-9.

5. Kandilakis C, Sasso-Lance E. Exoskeletons for personal use after spinal cord injury. Arch Phys Med Rehabil. 2021;102:331-7.

6. Contreras-Vidal JL, Bhagat NA, Brantley J, Cruz-Garza JG, He Y, Manley Q, et al. Powered exoskeletons for bipedal locomotion after spinal cord injury. J Neural Eng. 2016;13:031001.

7. Barbareschi G, Richards R, Thornton M, Carlson T, Holloway C. Statically vs dynamically balanced gait: analysis of a robotic exoskeleton compared with a human. Conf Proc IEEE Eng Med Biol Soc. 2015;2015:6728-31.

8. Ames A. Human-inspired control of bipedal walking robots. IEEE Trans Autom Control. 2014;59:1115-30.

9. Agrawal AHO, Hereid A, Finet $S$, Masselin M, Praly L, Ames AD, et al. First steps towards translating HZD control of bipedal robots to decentralized control of exoskeletons. IEEE Access. 2017;5:9919-34.

10. Gurriet TFS, Boeris G, Duburcq A, Hereid A, Harib O, Masselin M, et al. Towards restoring locomotion for paraplegics: realizing dynamically stable walking on exoskeletons. 2018 IEEE International Conference on Robotics and Automation (ICRA), 2018, pp. 2804-2811.

11. Bouhassira D, Attal N, Fermanian J, Alchaar H, Gautron $M$, Masquelier $E$, et al. Development and validation of the Neuropathic Pain Symptom Inventory. Pain 2004;108:248-57.

12. Krogh K, Christensen P, Sabroe S, Laurberg S. Neurogenic bowel dysfunction score. Spinal Cord. 2006;44:625-31.

13. Lewis SJ, Heaton KW. Stool form scale as a useful guide to intestinal transit time. Scand J Gastroenterol. 1997;32:920-4.

14. Costa P, Perrouin-Verbe B, Colvez A, Didier J, Marquis P, Marrel A, et al. Quality of life in spinal cord injury patients with urinary difficulties. Dev Valid qualiveen Eur Urol. 2001;39:107-13.

15. Borg GA. Psychophysical bases of perceived exertion. Med Sci Sports Exerc 1982;14:377-81.

16. Becker $M$, Jaschinski T, Eikermann $M$, Mathes $T$, Buhn $S$, Koppert W, et al. A systematic decision-making process on the need for updating clinical practice guidelines proved to be feasible in a pilot study. J Clin Epidemiol. 2018;96:101-9. 
17. Altman D. Statistics with confidence: Confidence Intervals and Statistical Guidelines. 2nd Edition ed: BMJ Books; 2000, pp 45-56.

18. Bland M. An introduction to Medical Statistics. Third Edition ed. USA: Oxford University Press; 2000, pp 14-52.

19. Kirshblum SC, Burns SP, Biering-Sorensen F, Donovan W, Graves DE, Jha A, et al. International standards for neurological classification of spinal cord injury (revised 2011). J Spinal Cord Med. 2011;34:535-46.

20. Louie DR, Eng JJ, Lam T. Spinal cord injury research evidence research T. Gait speed using powered robotic exoskeletons after spinal cord injury: a systematic review and correlational study. J Neuroeng Rehabil. 2015;12:82.

21. van Hedel HJ, Dietz V, Curt A. Assessment of walking speed and distance in subjects with an incomplete spinal cord injury. Neurorehabil Neural Repair. 2007;21:295-301.

22. Asselin P, Knezevic S, Kornfeld S, Cirnigliaro C, Agranova-Breyter I, Bauman WA, et al. Heart rate and oxygen demand of powered exoskeleton-assisted walking in persons with paraplegia. J Rehabil Res Dev. 2015;52:147-58.

23. Escalona MJ, Brosseau R, Vermette M, Comtois AS, Duclos C, Aubertin-Leheudre $M$, et al. Cardiorespiratory demand and rate of perceived exertion during overground walking with a robotic exoskeleton in long-term manual wheelchair users with chronic spinal cord injury: a cross-sectional study. Ann Phys Rehabil Med. 2018;61:215-23.

24. Huang Q, Yu L, Gu R, Zhou Y, Hu C. Effects of robot training on bowel function in patients with spinal cord injury. J Phys Ther Sci. 2015;27:1377-8.

25. Miller LE, Herbert WG. Health and economic benefits of physical activity for patients with spinal cord injury. Clinicoecon Outcomes Res. 2016;8:551-8.

26. Poritz JMP, Taylor HB, Francisco G, Chang SH. User satisfaction with lower limb wearable robotic exoskeletons. Disabil Rehabil Assist Technol. 2020;15:322-7.

27. Lynch SM, Leahy P, Barker SP. Reliability of measurements obtained with a modified functional reach test in subjects with spinal cord injury. Phys Ther. 1998;78:128-33.

28. Sprigle S, Maurer C, Holowka M. Development of valid and reliable measures of postural stability. J Spinal Cord Med. 2007;30:40-9.

29. Collot A. Le rôle joué par le muscle grand dorsal dans l'équilibre assis du paraplégique de niveau métamérique élevé,. Annales de Kinésithérapie. 1979;6:283-301.

30. Pearcey GEP, Zehr EP. Exploiting cervicolumbar connections enhances short-term spinal cord plasticity induced by rhythmic movement. Exp Brain Res. 2019;237:2319-29.
31. Zehr EP, Barss TS, Dragert K, Frigon A, Vasudevan EV, Haridas C, et al. Neuromechanical interactions between the limbs during human locomotion: an evolutionary perspective with translation to rehabilitation. Exp Brain Res. 2016;234:3059-81.

\section{ACKNOWLEDGEMENTS}

We would like to thank Amélie Durand, Caroline Soufflet, Pauline Beaumel, and all the Wandercraft team for their role in designing the Atalante exoskeleton and making the presented clinical trial possible. We would also like to thank Thomas Gurriet, Jessy Grizzle, Ayush Agrawal, Koushil Sreenath, Ayonga Hereid at the California Institute of Technology, University of Michigan, Ann Arbor, University of California Berkeley, and the Ohio State University who were instrumental in earlier studies and in the synthesis of dynamic walking algorithms and controllers.

\section{FUNDING}

This work has been supported by Wandercraft. The Atalante devices used were provided by the study sponsor.

\section{COMPETING INTERESTS}

The authors declare no competing interests.

\section{ADDITIONAL INFORMATION}

Correspondence and requests for materials should be addressed to J.K.

Reprints and permission information is available at http://www.nature.com/ reprints

Publisher's note Springer Nature remains neutral with regard to jurisdictional claims in published maps and institutional affiliations. 